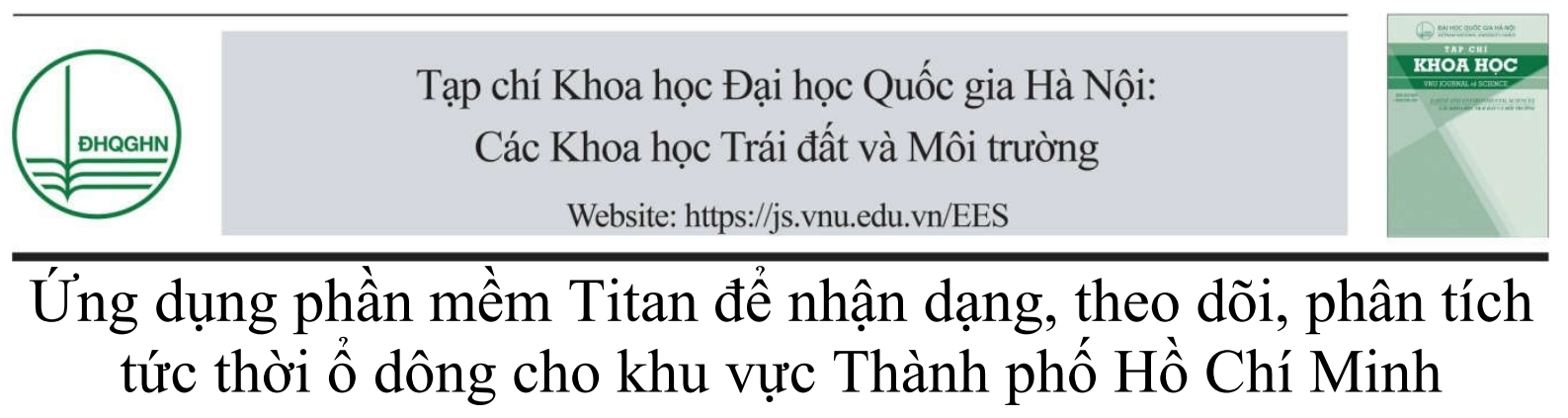

\author{
Công Thanh ${ }^{1, *}$, Võ Thị Nguyên ${ }^{2}$, Trần Duy Thức ${ }^{3}$ \\ ${ }^{1}$ Khoa Khi tuợng Thủy văn và Hải dương học, Truoòng Đại học Khoa học tụ nhiên, ĐHQGHN, \\ 334 Nguyến Trãi, Thanh Xuân, Hà Nội, Việt Nam \\ ${ }^{2}$ Phân viện Khoa học Khí tuợng Thủy văn và Biên đổi khí hậu, \\ 19 Nguyễn Thị Minh Khai, Quận 1, TP. Hồ Chí Minh, Việt Nam \\ Viện Khoa học Khi tuợng Thủy Văn và Biến đổi khi hậu, \\ 23/62 Nguyễn Chi Thanh, Đống Đa, Hà Nội, Việt Nam \\ Nhận ngày 30 tháng 11 năm 2018 \\ Chỉnh sửa ngày 10 tháng 12 năm 2018; Chấp nhận đăng ngày 25 tháng 12 năm 2018
}

\begin{abstract}
Tóm tắt: Bài báo này trình bày kết quả nghiên cứu ứng dụng phần mềm TITAN để nhận dạng, theo dõi, phân tích tức thời dông cho khu vực thành phố Hồ Chí Minh. Thuật toán Tstorms2Symprod trong phần mềm TITAN được sử dụng để xác định ổ dông và sự di chuyển ổ dông trong 1 giờ tới, thông qua độ phản hồi vô tuyến của ra đa Nhà Bè thời gian thực, dựa trên véc tơ làm trơn TREC. Việc tích phân theo thời gian sử dụng các sơ đồ bán thời gian Lagrange. Các sơ đồ tích phân này trong 60 phút cho ra 10 dự báo cách nhau khoảng 6 phút lần. Kết quả của phần mềm được kiểm chứng với số liệu quan trắc tại trạm, sản phẩm Cmax (độ phản hồi vô tuyến cực đại của ra đa) và ảnh mây vệ tinh Himawari-8. Nghiên cứu cho thấy phần mềm TITAN có thể nắm bắt được vị trí, hướng và vận tốc di chuyển, quy mô của các ổ dông. Điều này có ý nghĩa quan trọng trong dự báo mưa hạn cực ngắn cho khu vực thành phố Hồ Chí Minh.
\end{abstract}

Tù khóa: Phần mềm TITAN, ổ dông, Tstorms2Symprod.

\section{Giới thiệu}

Trong những năm gần đây, các sự kiện mưa lớn trong thời gian ngắn đã xảy ra trên khu vực thành phố Hồ Chí Minh với tần suất và cường độ ngày một lớn, thường gây ra ngập úng nghiêm trọng, tác động rất lớn đến kinh tế xã

\footnotetext{
* Tác giả liên hệ. ĐT.: 84-946180348.

Email: thanhc@vnu.edu.vn

https://doi.org/10.25073/2588-1094/vnuees.4331
}

hội. Đặc biệt, tính bất ngờ của những trận mưa lớn này là nguyên nhân chính dẫn đến những tai nạn không mong muốn đối với người dân trong khu vực. Vì vậy, việc theo dõi sự hình thành, phát triển, hướng di chuyển và khả năng gây mưa của các ổ dông phục vụ cho công tác dự báo các sự kiện mưa lớn này trở nên quan trọng. Trong thập niên 1970, Elvander (1976) [1] kết luận rằng ngoại suy tuyến tính bằng sự tương quan chéo là phương pháp đáng tin cậy nhất để thu được vectơ chuyển động cho một 
loạt các đặc trưng mưa đối lưu được thấy trong hình ảnh radar. Tuy nhiên, trong trường hợp mưa đối lưu, khi các tính chất ổ dông riêng lẻ có quy mô tương đối nhỏ và được xác định, ông lưu ý rằng ngoại suy bằng một ô vuông nhỏ nhất tuyến tính phù hợp với các vị trí trọng tâm trong quá khứ cho thấy hiệu quả. Vài thập kỷ sau, những kết luân này giải thích sự khác biệt cơ bản trong thiết kế thuật toán dự báo định lượng mưa (QPF) giữa một số hệ thống dự báo của Bắc Mỹ và Anh. Trong hội thảo về dự báo tức thời ổ dông đối lưu [2], Dixon đã giới thiệu mô hình titan và được sử dụng cho các nước như: Hoa Kì, Mexico, Đài Loan, Brazil, Úc, Nam Phi. Gần đây, phần mềm TITAN được ứng dụng trong công nghệ dự báo thời hạn ngắn và cực ngắn các vùng đối lưu hoạt động mạnh phục vụ cho dịch vụ khí tượng hàng không tại Trung Quốc [3].

TITAN có thể nhận dạng, theo dõi, phân tích và dự báo cực ngắn dông và mưa từ số liệu ra đa thời tiết. TITAN sử dụng các phương pháp ngẫu nhiên dựa trên số liệu chụp cắt lớp khối của đám dông ở thời điểm hiện tại và ngoại suy tuyến tính có trọng lượng từ tập số liệu lịch sử để xác định sự phát triển của đám dông tại thời điểm tiếp theo. TITAN hoạt động trên môi trường UNIX, LINUX và có thể hoạt động ở hai chế độ: thời gian thực và lịch sử. TITAN hiện đang được sử dụng rộng rãi trên thế giới phục vụ dự báo mưa với thời hạn cực ngắn, làm mưa nhân tạo, phá mưa đá và cảnh báo các cơn dông nguy hiểm. TITAN hoạt động trên dữ liệu ra đa quét khối trong hệ tọa độ Cartesian. Nó dựa trên giả thiết các ổ dông là miền ba chiều có độ phản hồi vượt quá ngưỡng $(30 \mathrm{dBz})$ và so sánh tính chất của các ổ dông tại thời điểm chụp cắt lớp và các thời điểm sau đó. Phương pháp này được gọi là phương pháp theo dõi trọng tâm. Quá trình dự báo dựa trên việc điều chỉnh hợp nhất một cách tuyến tính lịch sử phát triển của ổ dông cả về vị trí và kích thước, trên cơ sở đó ngoại suy tuyến tính cho tương lai. Vì vậy, nhóm tác giả nghiên cứu ứng dụng phần mềm TITAN để nhận dạng, theo dõi, phân tích tức thời dông từ độ phản hồi vô tuyến của ra đa Nhà Bè thời gian thực cho khu vực Thành phố Hồ Chí Minh. Bằng thuật toán Tstorms2Symprod, nghiên cứu xác định ổ dông, theo dõi và dự báo vị trí ổ dông theo xu hướng. Sau đó, sử dụng số liệu được thu thập từ 5 trạm đo mưa tự động, trạ khí tượng và trạm đo mưa nhân dân tại Thành phố Hồ Chí Minh, sản phẩm $C$ max của ra đa Nhà Bè và ảnh mây vệ tinh Himawari-8 với tần suất 10 phút/lượt được sử dụng để so sánh với kết quả ngoại suy của phần mềm TITAN.

\section{Phương pháp và số liệu}

\subsection{Phuơng pháp ngoại suy ổ dông bằng phần mềm TITAN}

Để xây dựng phương pháp ngoại suy ổ dông, các giả thiết được sử dụng: Ố dông có xu hướng chuyển động theo quỹ đạo thẳng; Ổ dông phát triển và suy giảm theo một xu thế tuyến tính; Quá trình sai lệch khỏi những điều trên xảy ra một cách ngẫu nhiên;

Thuật toán Tstorms2Symprod trong TITAN [4] được sử dụng để xác định ổ dông và sự di chuyển ổ dông thông qua độ phản hồi quá khứ dựa trên véc tơ làm trơn TREC (Tracking Radar Echoes by Correlation: Theo dõi sự phản hồi Radar bằng phép tương quan). Tái xử lý trường vận tốc thô $(\mathrm{u}, \mathrm{v})$ thông qua việc giảm thiểu $(\partial \mathrm{u}$ / $\partial \mathrm{x}+\partial \mathrm{v} / \partial \mathrm{y})$. Việc tích phân theo thời gian sử dụng các sơ đồ bán thời gian Lagrange [5]. Khi trường véc tơ được tính từ các sản phẩm CAPPI của ra đa liên tiếp 6 phút/ lần, các sơ đồ tích phân cho ra kết quả dự báo trong khoảng 6 phút/ lần.

- Phương pháp xác định ổ dông

Ổ dông là một miền liên tục có độ phản hồi lớn hơn một giá trị ngưỡng $T_{z}$ và thể tích của miền với độ phản hồi vượt quá một giá trị ngưỡng $T_{v}$. Giá trị $T_{z}$ xác định các dạng khác nhau của ổ dông. Ở đây, nghiên cứu chọn $T_{v}=50 \mathrm{~km}$ và $T_{z}$ $=30 \mathrm{dBz}$ (tương ứng với các quá trình mây đối lưu quy mô vừa). Việc sử dụng giá trị thể tích ngưỡng $T_{v}$ giúp loại nhiễu và giữ cho số lượng các ổ mây ở một số lượng vừa phải. Các cơn dông được xác dịnh bằng các đa giác (hình 1 ). 


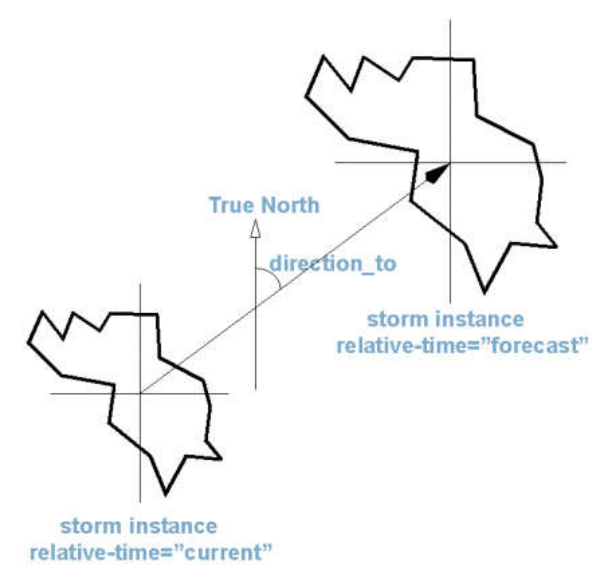

Hình 1. Các thuộc tính của ổ dông thời điểm hiện tại và dự báo, sử dụng đa giác [6].

- Theo dõi co bản: Khi các ổ dông đã được xác định, vào các thời điểm tuần tự $\left(\mathrm{t}_{0}\right.$ và $\mathrm{t}_{0}+6$ phút), chúng ta có thể ghép đôi chúng để liên kết thành các quỹ đạo. Tìm kiếm các vùng chồng chéo từ thời điểm này sang thời điểm tiếp theo. Các ổ dông hiện tại biểu thị màu trắng và các ổ dông từ lần quét trước đó có màu vàng.

- Dư báo vị trí ố dông dựa trên xu hưóng: Trong TITAN, tất cả các dự báo đều dựa trên các xu hướng ngoại suy ổ dông được quan trắc. Nghiên cứu thực hiện phép ngoại suy tuyến tính có trọng số thích hợp để theo dõi quá khứ. Quá khứ được hiển thị bằng màu vàng, vị trí hiện tại màu trắng và vị trí dự báo màu đỏ. Trong 30 phút TITAN thực hiện 5 dự báo cách nhau 6 phút/ lần. Có thể áp dụng dự báo dựa trên $x u$ hướng cho các thuộc tính ổ dông như khu vực (area) và độ phản hồi (volum).

- Đánh giá khả năng ngoại suy ổ dông của phần mềm TITAN: So sánh kết quả ngoại suy xuất ra từ phần mềm TITAN với sản phẩm Cmax (giá trị cực đại của độ phản hồi vô tuyến) của radar Nhà Bè thông qua sai số thống kê: Sai số trung bình ME, sai số trung bình tuyệt đối MAE, sai số trung bình toàn phương RMSE.

\subsection{Số liệu sử dụng}

Số liệu độ phản hồi vô tuyến của radar Nhà Bè lúc 19h00, 19h15, 19h30, 19h45 ngày 17/10/2016 được đưa vào phần mềm TITAN:
Bảng 1. Thông tin trận mưa tối ngày 17/10/2016 tại Thành phố Hồ Chí Minh

\begin{tabular}{lcc}
\hline \multicolumn{1}{c}{ Tên trạm } & Thời gian & $\begin{array}{c}\text { Lượng mưa } \\
\text { (mm) }\end{array}$ \\
\hline Quang Trung & $18: 30-19: 45$ & 50,5 \\
Lý Thường Kiệt & $18: 00-19: 45$ & 69,2 \\
Cầu Bông & $18: 00-21: 30$ & 23,4 \\
Phan Văn Khỏe & $18: 30-20: 00$ & 51,6 \\
Tân Quy Đông & $19: 00-22: 00$ & 17,2 \\
\hline
\end{tabular}

Số liệu độ phản hồi vô tuyến được thu thập tương ứng với trận mưa lớn ngày 17/10/2016. Với bán kính quét của radar là $240 \mathrm{~km}, 480 \mathrm{~km}$ và chu kỳ quan trắc, lưu số liệu 15 phút/lần. Radar Nhà Bè được đặt tại Ấp 3, xã Long Thới, huyện Nhà Bè, thành phố Hồ Chí Minh; tọa độ: $10^{\circ} 39^{\prime} 31^{\prime \prime} \mathrm{N}$ và $106^{\circ} 43^{\prime} 42^{\prime \prime} \mathrm{E}$. Loại radar là radar thời tiết Doppler DWSR-2500C.

Dữ liệu quan trắc mưa để đối chứng: Số liệu này được thu thập từ 5 trạm đo mưa tự động, trạm khí tượng và trạm đo mưa nhân dân tại Thành phố Hồ Chí Minh. Số liệu do Trung tâm chống ngập cung cấp (http://www.ttcn.hochiminhcity.gov.vn). Các trạm này bao gồm: Lý Thường Kiệt, Quang Trung, Cầu Bông, Phan Văn Khỏe, quận 7 (Tân Quy Đông).Cơn mưa lớn kết hợp triều cường vào tối ngày 17/10/2016 làm ngập nhiều tuyến đường tại $\mathrm{Tp}$. Hồ Chí Minh. Theo số liệu cung cấp của Trung tâm Chống ngập Tp. Hồ Chí Minh, mưa lớn kéo dài từ 18 giờ 00 phút đến 20 giờ 00 phút, tại Tân Quy Đông (quận 7) ghi nhận mưa kéo dài đến tận 22 giờ 00 phút.

Ảnh mây vệ tinh Himawari-8 với tần suất 10 phút/lượt được sử dụng để so sánh với kết quả ngoại suy của phần mềm TITAN (http://www.jma.go.jp/en/gms/).

\section{Kết quả ngoại suy ổ dông}

\subsection{Kết quả ngoại suy ổ dông}

Kết quả từ phần mềm TITAN với ngưỡng phản hồi (Zmax) là $30 \mathrm{dBz}$, TITAN đã bắt được hai ổ dôngnhư trên hình 2-a (lúc 19h00). Với thông số lần lượt: Ố dông số 1: cách radar Nhà Bè $7,5 \mathrm{~km}$ về hướng Tây Bắc, với $Z$ max là 
$49 \mathrm{dBz}$. Ổ dông số 2 : cách radar Nhà Bè $3 \mathrm{~km}$ về hướng Đông Bắc, với độ phản hồi cao nhất là $56 \mathrm{dBz}$. Đến thời điểm $19 \mathrm{~h} 15$ phút cùng ngày (hình $2 \mathrm{~b}$ ), phần mềm bắt được một ổ dông biểu thị bằng đa giác màu xanh dương. Ổ dông này là do sát nhập của hai ổ dông trước đó được biểu thị bằng đa giác màu vàng. Thông số của ổ dông sát nhập này như sau: cách radar Nhà Bè $6 \mathrm{~km}$ về hướng Bắc Tây Bắc, với Zmax là $56 \mathrm{dBz}$. Cũng trong Hình $2 \mathrm{~b}$ có thể dự báo ổ mây sẽ di chuyển theo hướng Tây Bắc, với vận tốc là $2 \mathrm{~km} / \mathrm{h}$, thể hiện bằng đa giác màu đỏ.

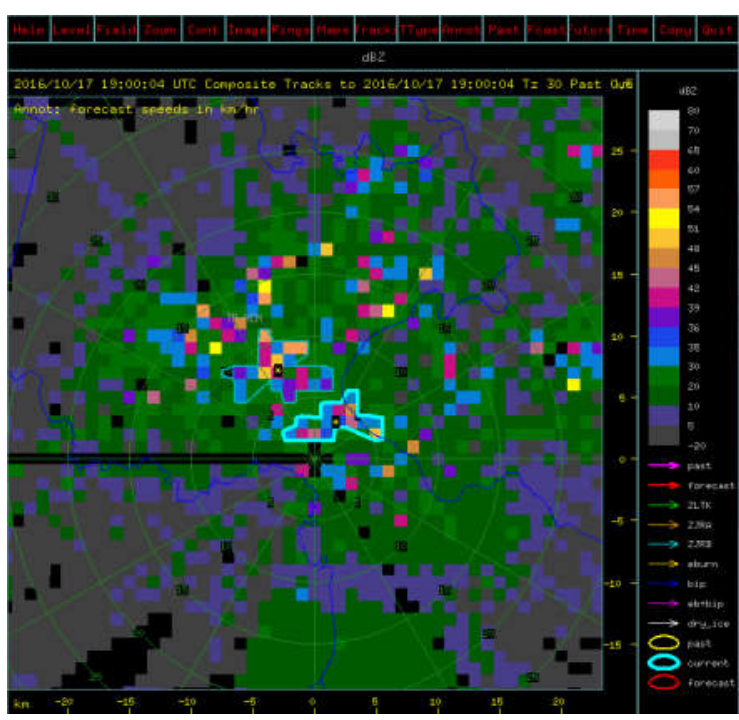

a.

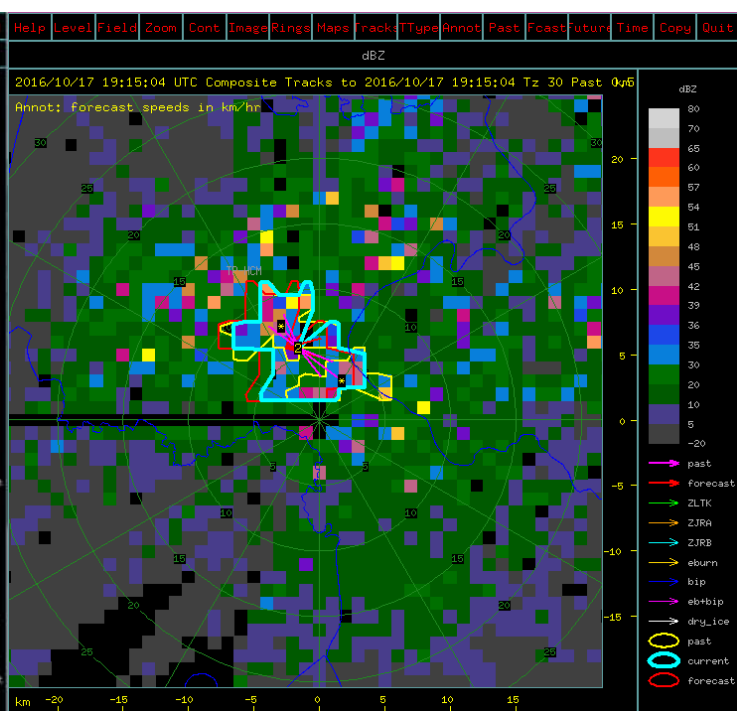

b.

Hình 2. Sản phẩm từ phần mềm TITAN lúc 19 h00 (a) và 19 h15 (b) ngày 17/10/2016 (ổ dông màu vàng là quá khứ; màu xanh là hiện tại, màu đỏ là ngoại suy, mũi tên đỏ thể hiện hướng di chuyển của ổ dông).

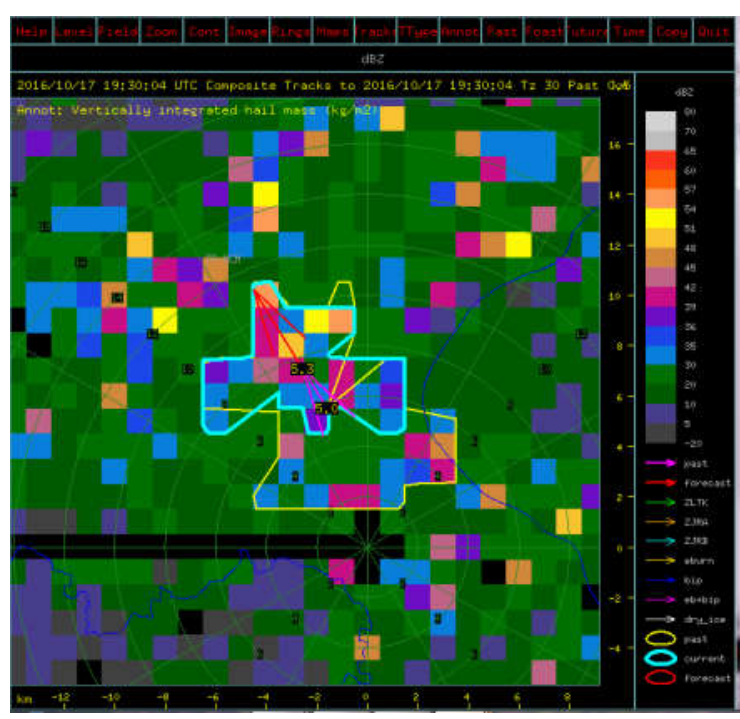

a.

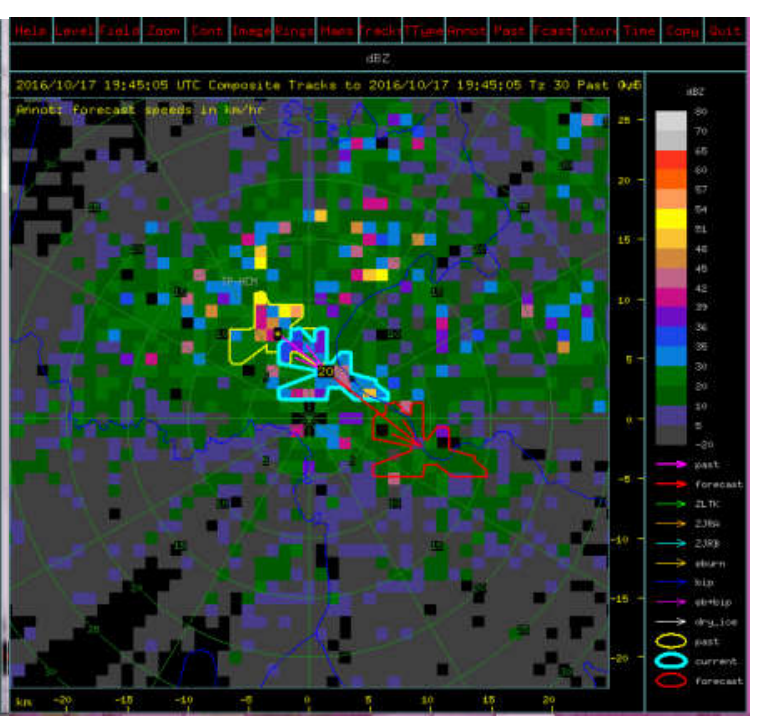

b.

Hình 3. Sản phẩm từ phần mềm TITAN lúc $19 h 30$ (trái) và 19 h45 (phải) ngày 17/10/2016 (ổ dông màu vàng là quá khứ; màu xanh là hiện tại, màu đỏ là ngoại suy, mũi tên đỏ thể hiện hướng di chuyển của ổ dông). 


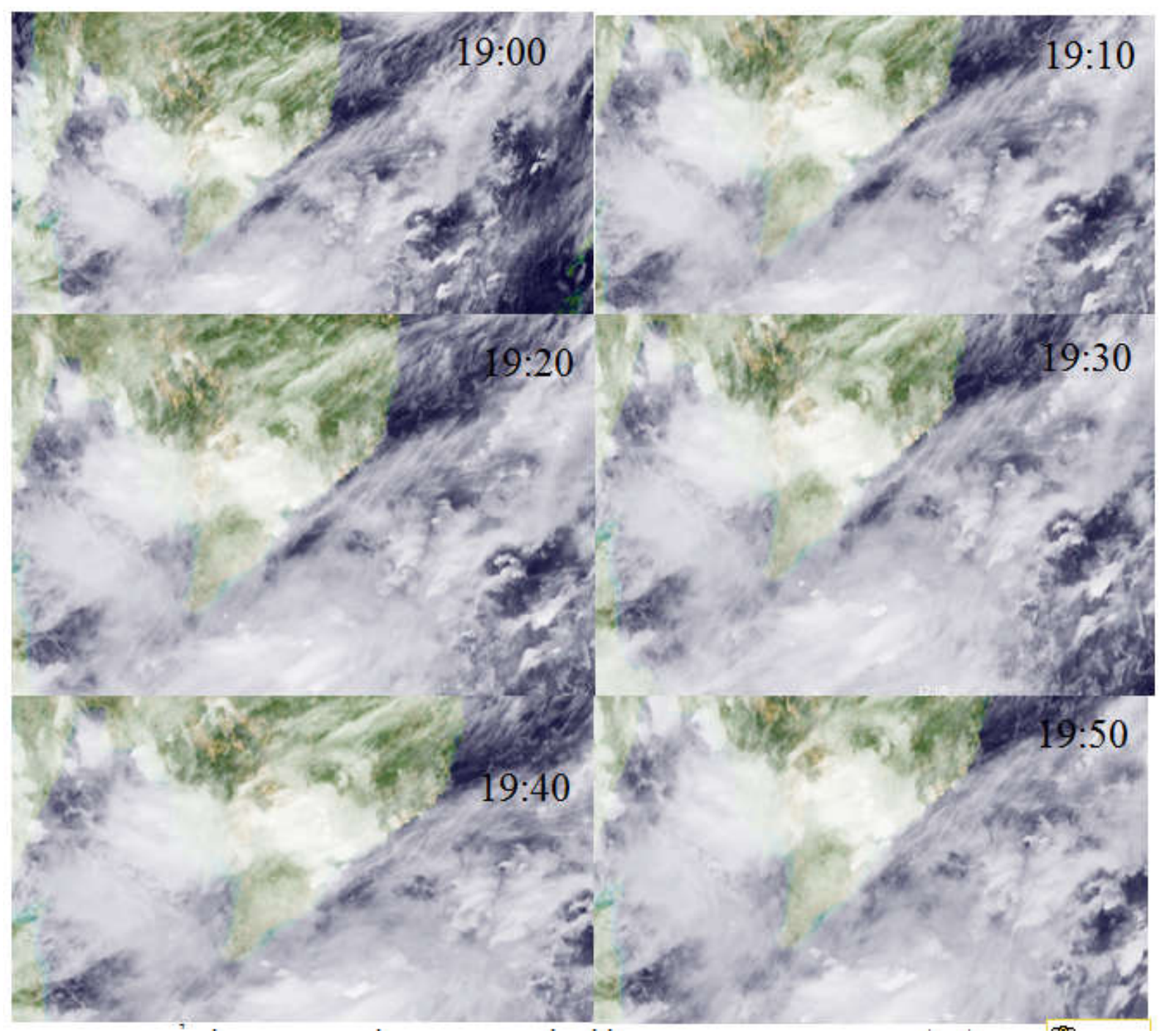

Hình 4. Ảnh mây vệ tinh Himawari cho khu vực Nam Bộ ngày 17/10/2016.

Vào thời điểm $19 \mathrm{~h} 30$ phút cùng ngày (Hình 3a), phần mềm tiếp tục theo dõi ổ dông sát nhập trên biểu thị bằng đa giác màu xanh dương. Thông số của ổ dông này như sau: cách radar Nhà Bè $19 \mathrm{~km}$ về hướng Tây Bắc, với Zmax là $57 \mathrm{dBz}$. Ổ dông đã di chuyển đúng theo hướng dự báo so với thời điểm 19 h15 và thu nhỏ diện tích.

Sang đến thời điểm $19 \mathrm{~h} 45$ phút cùng ngày (Hình $3 b$ ) phần mềm tiếp tục theo dõi ổ dông sát nhập. Thông số như sau: cách radar Nhà Bè $10 \mathrm{~km}$ về hướng Bắc Đông Bắc, với $Z$ max là $48 \mathrm{dBz}$. Tổng lượng chất lỏng VIL và khối lượng hạt mưa đều giảm đáng kể. Như vậy có thể dự báotrong thời điểm từ $19 \mathrm{~h} 30$ đến $19 \mathrm{~h} 45$ ổ dông đã gây mưa cho khu vực trung tâm Tp. Hồ Chí Minh. Theo dự báo, ổ mây sẽ đồi hướng, di chuyển về phía Đông Nam với vận tốc rất nhanh $20 \mathrm{~km} / \mathrm{h}$ so với thời điểm hiện tại. Trong 1 giờ tiếp theo sẽ gây mưa cho khu vực Cần Giờ.

Ảnh mây vệ tinh Himawari-8 được thu thập tại các thời điểm 19h00, 19h10, 19h15, 19h20, 19h30, 19h40, 19h50 nhằm đánh giá khả năng dự báo của phần mềm TITAN. Trên ảnh mây vệ tinh phát hiện khối mây dày đặc tại khu vực 
Đông Nam Bộ, tồn tại trong khoảng thời gian từ 19 h00 đến 19 h50 ngày 17/10/2016.

\section{Nhận xét:}

So sánh với dữ liệu mưa quan trắc tại trạm (Bảng 1) và ảnh mây vệ tinh Himawari-8 (Hình 4) ta có những nhận xét sau: Như vậy sản phẩm từ phần mềm TITAN có thể nắm bắt được vị trí và hướng đi của các ổ dông. So sánh với số liệu thực tế tại Bảng 2, có thể thấy trạm Lý Thường Kiệt ở khu vực phía Tây Bắc trạm Nhà Bè và trạm Cầu Bông phía Đông Bắc Trạm Nhà Bè có mưa bắt đầu từ $18 \mathrm{~h} 00$, tiếp theo đó khi ổ dông di chuyển về phía Tây Bắc, số liệu cũng cho thấy trạm Quang Trung có mưa trễ pha hơn lúc 18h30. Khi ổ mây di chuyển ngược lại theo hướng Đông Nam lần lượt gây mưa tại trạm Phan Văn Khỏe (quận 6) và mưa đến muộn hơn ở trạm Tân Quy Đông (quận 7). TITAN còn xác định được các thông số của ồ dông, cho thấy quy mô và khả năng gây mưa của các ổ dông là khác nhau. Tại cùng thời điểm, nhưng ổ dông phía Tây Bắc có quy mô lớn hơn ổ dông phía Đông Bắc, điều này trùng khớp với số liệu mưa ghi được của trạm Cầu Bông nhỏ hơn trạm Lý Thường Kiệt dù thời gian mưa tại trạm Cầu Bông là dài hơn.

\section{2 Đánh giá kết quả của phầm mềm TITAN}

Sản phẩm của thuật toán ngoại suy 1 giờ Tstorms2Symprod thu được từ phần mềm TITAN được so sánh với sản phẩm CMAX (giá trị cực đại của PHVT theo mỗi cột khí quyển trên một đơn vị diện tích) của Radar Nhà Bè. Kết quả được thể hiện trên bảng 2 .

Bảng 2. Kết quả thuật toán ngoại suy ổ dông từ phần mềm TITAN cho ngày 17/10/2016 tại các trạm thuộc khu vực thành phố Hồ Chí Minh.

\begin{tabular}{cccccccccccc}
\hline \multirow{2}{*}{ Trạm } & Lat & Long & \multicolumn{4}{c}{ TITAN } & \multicolumn{5}{c}{ CMAX } \\
\cline { 4 - 11 } & & & $20: 00$ & $20: 15$ & $20: 30$ & $20: 45$ & $20: 00$ & $20: 15$ & $20: 30$ & $20: 45$ \\
\hline Cần Giờ & 10,38 & 106,91 & 0,72 & 0,00 & 0,00 & 0,00 & 0,33 & $-0,57$ & 0,12 & $-0,25$ \\
Củ Chi & 11,04 & 106,42 & 9,53 & 9,22 & 8,51 & 9,56 & 7,07 & 5,04 & 15,03 & 11,09 \\
Quận 8-1 & 10,87 & 106,69 & $-1,32$ & 2,91 & $-0,52$ & 0,00 & 4,08 & 6,39 & 10,83 & 11,02 \\
Tân Thông Hội & 10,94 & 106,50 & 11,74 & 9,17 & 9,22 & 8,06 & 9,03 & 12,53 & 7,63 & 4,63 \\
Bình Tân & 10,73 & 106,61 & 29,60 & 32,46 & 0,00 & 28,60 & 22,84 & 23,22 & 25,74 & 22,63 \\
Quận 7 & 10,72 & 106,74 & 34,23 & 35,45 & 35,27 & 37,02 & 31,02 & 30,28 & 34,93 & 26,83 \\
Quận 12 & 10,73 & 106,64 & 27,07 & 27,77 & 27,55 & 0,00 & 27,18 & 33,73 & 29,29 & 15,29 \\
Quận 8-2 & 10,88 & 106,69 & 0,08 & 3,65 & 2,05 & 0,09 & 0,64 & 4,92 & 4,92 & 0,18 \\
Tân Sơn Hòa & 10,79 & 106,66 & 15,79 & 13,74 & 10,55 & 10,42 & 16,83 & 20,83 & 20,20 & 25,03 \\
Nhà bèn & 10,66 & 106,73 & 0,00 & 0,00 & 0,00 & 0,00 & 0,00 & 0,00 & 0,00 & 0,00 \\
Mạc Đĩnh Chi & 10,78 & 106,70 & 25,26 & 29,10 & 27,04 & 24,14 & 18,02 & 17,36 & 18,39 & 19,02 \\
Tân Sơn Nhất & 10,81 & 106,68 & 15,96 & 16,13 & 15,22 & 15,18 & 11,64 & 14,73 & 24,02 & 20,85 \\
Thanh Đa & 10,82 & 106,74 & 37,63 & 29,31 & 6,28 & 4,12 & 35,73 & 28,93 & 24,02 & 23,45 \\
Lýy Thường Kiệt & 10,77 & 106,66 & 38,05 & 40,24 & 25,58 & 26,52 & 37,63 & 35,20 & 37,93 & 30,02 \\
Quang Trung & 10,84 & 106,66 & 4,51 & $-1,61$ & $-1,31$ & $-0,66$ & 3,67 & 0,48 & $-0,74$ & 0,37 \\
Cầu Bông & 10,79 & 106,76 & 26,29 & 27,03 & 27,14 & 26,29 & 25,02 & 28,02 & 25,02 & 25,74 \\
Phước Long & 10,83 & 106,77 & 27,16 & 23,48 & 27,82 & 24,60 & 25,93 & 24,02 & 24,37 & 19,05 \\
Phan Văn Khỏe & 10,75 & 106,66 & 28,98 & 32,43 & 30,57 & 35,66 & 30,73 & 32,93 & 30,63 & 34,73 \\
\hline
\end{tabular}


Bảng 3. Đánh giá kết quả ngoại suy ổ dông của phần mềm TITAN ngày 17/10/2016(dBz).

\begin{tabular}{llll}
\hline Ngày 17/10/2016 & ME & MAE & RMSE \\
\hline TITAN & 1,12 & 4,24 & 1,05 \\
\hline
\end{tabular}

Nhận xét:

Từ số liệu xuất ra của phầm mềm TITAN, so sánh với CMAX thông qua các chỉ số thống kê ta thấy: Chỉ số ME thể hiện giá trị dương $(1,12 \mathrm{dBZ})$, điều đó chứng tỏ kết quả ngoại suy từ phần mềm cho giá trị lớn hơn so với thực tế. Giá trị của MAE cho biết mức độ lệch trung bình của sản phẩm từ phần mềm TITAN so với CMAX là $4,24 \mathrm{dBz}$. Sai số bình phương trung bìnhtrong ngoại suy độ phản hồi tại các trạm với sản phẩm CMAX là $1,05 \mathrm{dBz}$.

\section{Kết luận}

Trong phạm vi của nghiên cứu là khu vực thành phố Hồ Chí Minh, từ kết quả phân tích trên bài báo đưa ra một vài kết luận như sau: Sản phẩm từ phần mềm TITAN có thể nắm bắt được vị trí và hướng đi của các ổ dông. Đồng thời, còn xác định được các thông số của ồ dông, cho thấy quy mô và khả năng gây mưa của các ổ dông là khác nhau. Các chỉ số thống kê cho thấy, phần mềm cho độ phản hồi cao hơn giá trị CMAX, sai số hệ thống nhỏ là cơ sở để hiệu chỉnh phần mềm. Khi so sánh với ảnh mây vệ tinh, sản phẩm của phần mềm TITAN có độ phân giải cao hơn và có khả năng dự báo đến từng điểm trạm. Bước đầu cho thấy TITAN phù hợp để sử dụng trong nghiệp vụ dự báo mưa lớn hạn cực ngắn cho khu vực TP. Hồ Chí Minh.

\section{Lời cảm ơn}

Nghiên cứu này được thực hiện và hoàn thành nhờ sự hỗ trợ của Đề tài "Xây dựng hệ thống nghiệp vụ dự báo mưa lớn hạn cực ngắn trên địa bàn Thành phố Hồ Chí Minh". Tác giả xin chân thành cảm ơn.

\section{Tài liệu tham khảo}

[1] Elvander, R.C (1976),An evaluation of the relative performance of three weather radarecho forecasting techniques. Preprints $17^{\text {th }}$ Conference on Radar Meteorology, Sealtle, WA, pp, 526-532. American Meteorological Society, Boston.

[2] Dixon, 2011. Titan: Workshop on Techniques for Convective Storm Nowcasting, report.

[3] Xinhua Liu, 2017. The short-time forecasting and nowcasting technology of severe convective weather for aviation meteorological services in China, report.

[4] Dixon, M. and Weiner, G. 1993. TITAN: Thunderstorm Identification, Tracking, Analysis and Nowcasting - A radar based methodology, J.Atmos.Oceanic Technol., 10, 785-797.

[5] Staniforth, A. and Cote, J. (1991) SemiLagrangian Integration Schemes for Atmospheric Models-A Review. Monthly Weather Review, 119, 2206-2223.

[6] Dixon M. and Seed B. (2014). Developments in echo tracking - enhancing TITAN. ERA 2014-The eighth European conference on radar in meteorology and hydrology. 


\title{
Application of Titan Software for Recognition, Monitoring, Instantaneous Analysis of Thunderstorm for Ho Chi Minh City
}

\author{
Cong Thanh ${ }^{1}$, Vo Thi Nguyen ${ }^{2}$, Tran Duy Thuc ${ }^{3}$ \\ ${ }^{I}$ Faculty of Hydro-Meteorology and Oceanography, VNU University of Science \\ 334 Nguyen Trai, Thanh Xuan, Thanh Xuan, Hanoi, Vietnam \\ ${ }^{2}$ Sub-Institute of Meteorology Hydrology and Climate Change, \\ 19 Nguyen Thi Minh Khai, District 1, Ho Chi Minh City, Vietnam \\ ${ }^{3}$ Viet Nam Institute of Meteorology Hydrology and Climate Change, \\ 23/62 Nguyen Chi Thanh, Dong Da, Hanoi, VietNam
}

\begin{abstract}
This paper presents the identification, monitoring and Instantaneous analysis of thunderstorms over Ho Chi Minh City area using TITAN software. The Tstorms2Symprod algorithm in TITAN is used to determine the thunderstorm cells and movement of the thunderstorm cells in the next hour, through the real-time reflectivity, based on smoothing of the TREC vectors. Integral along time using Lagrange diagrams. These integral diagrams within 60 minutes create 10 products every 6 minutes. The results of this software is validated with observation data at the station, the Cmax product (radar maximum reflectivity) and the Himawari 8 satellite image. The results show that the TITAN model can capture the location, direction and velocity, and the scale of the thunderstorm cells. This is important for very short-range precipitation forecast for Ho Chi Minh City.
\end{abstract}

Keywords: TITAN, tstorms2Symprod, thunderstorms. 